\title{
Association of Preoperative Hemoglobin A1c with In-hospital Mortality Following Valvular Heart Surgery
}

Mohammadreza Shoghli ${ }^{1}$, MD; Rajesh Jainn², MD; Mohamamdali Boroumand ${ }^{1}$, MD; Shayan Ziaee ${ }^{1}$, PhD; Aras Rafiee $^{3}$, PhD; Leyla Pourgholi ${ }^{1}, \mathrm{MD}$; Akbar Shafiee ${ }^{1}, \mathrm{MD}, \mathrm{MSc}$; Arash Jalali ${ }^{1}, \mathrm{PhD}$; Seyedeh Hamideh Mortazavi ${ }^{1}$, MD; Seyed Hossein Ahmadi Tafti ${ }^{1}$, MD

DOI: $10.21470 / 1678-9741-2019-0320$

\begin{abstract}
Objective: To determine the association between the preoperative level of hemoglobin A1c (HbA1c) and in-hospital mortality in patients who underwent valvular heart surgery in our center in a retrospective cohort.

Methods: In this retrospective consecutive cohort study, patients with type 2 diabetes mellitus who were referred to our center for elective valvular surgery were enrolled and followed up. The endpoint of this study was in-hospital mortality. Based on the level of $\mathrm{HbA1C}$, patients were dichotomized around a level of $7 \%$ into two groups: exposed patients with $\mathrm{HbA} 1 \mathrm{c} \geq 7 \%$ and unexposed patients with $\mathrm{HbA} 1 \mathrm{c}<7 \%$. Then, the study variables were compared between the two groups.

Results: Two hundred twenty-four diabetic patients who were candidates for valvular surgery were enrolled; 106 patients $(47.3 \%)$
\end{abstract}

had $\mathrm{HbA1C}<7 \%$, and 118 patients $(52.6 \%)$ had $\mathrm{HbA} 1 \mathrm{c} \geq 7 \%$. The duration of diabetes was higher in patients with $\mathrm{HbA} 1 \mathrm{c} \geq 7 \%$ $(P=0.007)$. Thirteen $(5.8 \%)$ patients died during hospital admission, of which nine patients were in the high HbA1c group. There was no significant difference between the groups regarding inhospital mortality $(P=0.899)$. Both the unadjusted and adjusted logistic regression models showed that $\mathrm{HbA1c}$ was not a predictor for in-hospital mortality ( $P=0.227$ and $P=0.388$, respectively)

Conclusion: This study showed no association between preoperative HbA1c levels and in-hospital mortality in candidates for valvular heart surgery.

Keywords: Diabetes Mellitus, Type 2. Glycated Hemoglobin A. Hospital Mortality. Cardiac Surgical Procedures. Elective Surgical Procedures. Blood Glucose, Hospitalization.

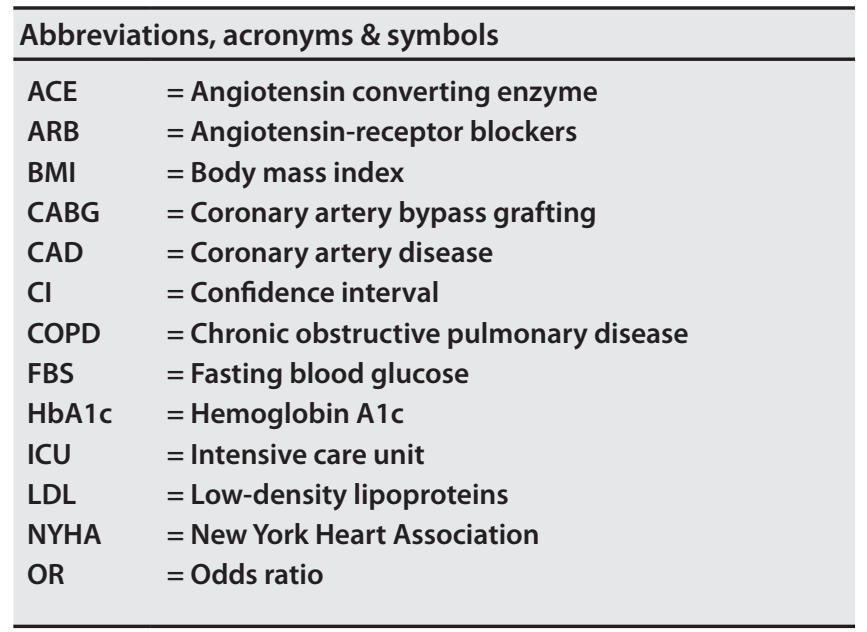

'Tehran Heart Center, Cardiovascular Diseases Research Institute, Tehran University of Medical Sciences, Tehran, Iran.

2Jain Hospital, Kanpur, India.

${ }^{3}$ Department of Biology, Central Tehran Branch, Islamic Azad University, Tehran, Iran.

This study was carried out at the Tehran Heart Center, Tehran University of Medical Sciences, Tehran, Iran.

\section{INTRODUCTION}

The global incidence and prevalence of diabetes mellitus are dramatically increasing in recent years, and in 2011, almost $25 \%$ of the Iranian population had impaired fasting glucose or diabetes mellitus ${ }^{[1,2]}$. Control of blood glucose in patients who undergo any surgical operation is crucial as diabetes mellitus has been linked to the development of many adverse outcomes following open-heart surgeries, such as sepsis, wound infection, cerebrovascular accidents, postoperative atrial fibrillation, and mortality ${ }^{[3-6]}$. Therefore, a valid and reliable marker for the evaluation of diabetes control can help much to reduce these complications.

Hemoglobin A1c ( $\mathrm{HbA1c}$ ) has been introduced as a useful marker that can show the situation of glucose control in the past 8-12 weeks before the evaluation ${ }^{[7]}$. Hyperglycemia, as detected

Correspondence Address:

Seyed Hossein Ahmadi Tafti

iD https://orcid.org/0000-0002-9315-2809

Tehran Heart Center

North Kargar Ave, Tehran, Iran

Zip Code: 1411713138

E-mail:ahmadita@sina.tums.ac.ir 
by elevated $\mathrm{HbA1c}$, has been shown to be linked with major adverse events following cardiac surgery, ranging from sternal infection to death ${ }^{[8]}$. However, this effect was mostly observed in patients who underwent coronary artery bypass grafting (CABG), and data about the effect of hyperglycemia on valvular heart surgery is scarce.

Therefore, we aimed to determine the association between the level of HbA1c and in-hospital mortality in patients who underwent valvular heart surgery in our center in a retrospective cohort.

\section{METHODS}

In this retrospective cohort study, consecutive patients with type 2 diabetes mellitus who were referred to our center for elective valvular surgery were enrolled and followed up. The inclusion criteria were: 1) being a candidate for valvular heart surgery alone; 2) having established type 2 diabetes; and 3) giving informed consent for taking part in the study. The exclusion criteria were: 1) emergency surgery; 2) history of cardiac surgery; 3) simultaneous $C A B G$; 4) history of chronic inflammatory disease, malignancy, or hepatic failure; and 5) history of hemolytic anemia, hemoglobinopathy, or recent massive bleeding. Based on our hospital policy, all of the patients signed a written informed consent at the time of their admission, allowing anonymous use of their clinical data for research purposes. Our study protocol was approved by the Research Board and committee of Medical Ethics of the Tehran Heart Center. This study was performed in accordance with the latest version of the declaration of Helsinki.

All of the demographic and clinical data of the patients were retrieved from the cardiac surgery database of the Tehran Heart Center ${ }^{[9]}$. At the time of admission, the height and weight of the patients were measured, and body mass index was calculated for every patient. A thorough history of habits, cardiac risk factors, and previous medical conditions was also obtained and recorded. Transthoracic echocardiography was performed before the operation, and the patients' ejection fraction was used for this study.

On the day of the surgery, a fasting venous blood sample was obtained from every patient for biochemistry tests, especially fasting blood glucose (FBS) and HbA1c. These measurements were performed by turbidimetric inhibition immunoassay using Cobas Integra 400 plus.

Valvular surgeries were performed under the highest standards in the operation room of the Tehran Heart Center. After anesthesia and prep and drape, a median sternotomy was performed. The aorta, superior vena cava, and inferior vena cava were emulated. Based on the valvular problem, the patients underwent valvular replacement or repair in one or more valves.

Following surgery, all patients underwent cardiac monitoring in the intensive care unit (ICU) and the post-ICU ward for the development of any complication, particularly mortality. Based on the level of $\mathrm{HbA} 1 \mathrm{c}$, patients were dichotomized around a level of $7 \%$ into two groups: exposed patients with $\mathrm{HbA} 1 \mathrm{c} \geq 7 \%$ and unexposed patients with $\mathrm{HbA} 1 \mathrm{c}<7 \%$. Then, the study variables, including the frequency of mortality, were compared between the two groups. The endpoint of this study was in-hospital mortality.

\section{Statistical Analysis}

Mean \pm standard deviation or median with quartiles and frequency (percentage) were used to describe continuous and categorical variables, respectively. Continuous variables were compared between HbA1c groups using Student's t-test or Mann-Whitney $U$ test. Categorical variables were compared between the mentioned groups using the chi-square or Fisher's exact test. The association of Hbalc levels and mortality was adjusted on detected possible confounders in this study using a logistic regression model, and it was expressed as an odds ratio (OR) with a 95\% confidence interval (Cl). P-values $\leq 0.05$ were considered statistically significant. The IBM SPSS Statistics software, version 21.0 (Microsoft, United States of America), was used for statistical analyses.

\section{RESULTS}

In this study, 224 diabetic patients who were candidates for valvular surgery were enrolled. Mitral and tricuspid valves were the most common valves that were operated, and in 112 patients, more than one valve was operated (Table 1). One hundred six patients (47.3\%) had $\mathrm{HbA} 1 \mathrm{c}<7 \%$ and 118 patients (52.6\%) had $\mathrm{HbA} 1 \mathrm{c} \geq 7 \%$. There was no significant difference between the groups in demographic and clinical characteristics, including cardiovascular risk factors (Table 2). However, the levels of triglyceride and total cholesterol were significantly higher in patients with high $\mathrm{HbA} 1 \mathrm{c}$ ( $P<0.001$ and $P=0.005$, respectively). The groups were not statistically different regarding other laboratory indices, ventilation time, and ICU admission.

The median duration of hospital stay was 13.4 days, and 13 (5.8\%) patients died during hospital admission, of which nine patients were in the high $\mathrm{HbA} 1 \mathrm{c}$ group. Five patients died due to heart failure, four patients had sternal wound infection, one patient had gastrointestinal bleeding, one patient developed acute respiratory distress syndrome, one patient had sepsis, and one patient developed cerebrovascular accident during hospitalization. However, there was no significant difference between the groups regarding in-hospital mortality $(P=0.899)$. The unadjusted logistic regression model showed that $\mathrm{HbA1C}$ was not a predictor for in-hospital mortality (OR: 2.1, Cl: 0.62-7.05; $P=0.227$ ) (Table 3). After adjustment for age, duration of diabetes, triglyceride, and low-density lipoprotein, $\mathrm{HbA} 1 \mathrm{c}$ did not present any association with in-hospital mortality (OR: 2.07, Cl: 0.39-10.91; $P=0.388$ ) (Table 3).

\section{DISCUSSION}

This study aimed to find the association between $\mathrm{HbA} 1 \mathrm{c}$ levels and mortality following valvular heart surgery. However, we did not observe this association.

High blood glucose at the time of surgery has been reported as a risk factor for developing adverse events, such as longer ICU stay, longer ventilation time, and atrial fibrillation following openheart surgery ${ }^{[10]}$. It has been shown that tight blood glucose control at the time of heart surgery has been accompanied by lower adverse outcomes following $\mathrm{CABG}^{[11]}$. The only study that was solely performed on patients with valvular heart surgery also 
Table 1. Frequency of the types of valvular surgery in the study population $(n=224)$.

\begin{tabular}{|c|c|}
\hline Valve/type of surgery & Frequency (percentage) \\
\hline Aortic valve & $89(39.7)$ \\
\hline Replacement & $82(36.6)$ \\
\hline Reconstruction & $3(1.3)$ \\
\hline Repair & $4(1.8)$ \\
\hline Mitral valve & $147(65.6)$ \\
\hline Annuloplasty & $4(1.8)$ \\
\hline Repair & $135(60.3)$ \\
\hline Reconstruction with annuloplasty & $3(1.3)$ \\
\hline Reconstruction without annuloplasty & $5(2.2)$ \\
\hline Pulmonary valve & $7(3.1)$ \\
\hline Repair & $5(2.2)$ \\
\hline Reconstruction & $2(0.9)$ \\
\hline Tricuspid valve & $93(41.5)$ \\
\hline Annuloplasty & $42(18.8)$ \\
\hline Replacement & $24(10.7)$ \\
\hline Reconstruction with annuloplasty & $6(2.7)$ \\
\hline Reconstruction without annuloplasty & $21(9.4)$ \\
\hline
\end{tabular}

Table 2. Comparison of the baseline study variables between the study groups.

\begin{tabular}{|c|c|c|c|}
\hline Characteristic* & $\begin{array}{l}\text { Controlled diabetes } \\
\qquad(n=106)\end{array}$ & $\begin{array}{l}\text { Uncontrolled diabetes } \\
\qquad(n=118)\end{array}$ & $P$-value \\
\hline Age, years & $60.5 \pm 8.7$ & $58.0 \pm 8.9$ & 0.034 \\
\hline Male gender, n (\%) & $33(31.1)$ & $38(32.2)$ & 0.863 \\
\hline $\mathrm{BMI}, \mathrm{kg} / \mathrm{m}^{2}$ & $27.0 \pm 4.7$ & $27.3 \pm 4.8$ & 0.642 \\
\hline Hypertension, n (\%) & $55(51.9)$ & $65(55.1)$ & 0.632 \\
\hline Dyslipidemia, n (\%) & $56(52.8)$ & $72(61.0)$ & 0.216 \\
\hline Family history of CAD, n (\%) & $36(34.0)$ & $32(27.1)$ & 0.266 \\
\hline Smoking, n (\%) & $5(4.7)$ & $5(4.2)$ & 0.999 \\
\hline COPD, n (\%) & $9(8.5)$ & $5(4.2)$ & 0.189 \\
\hline Duration of diabetes, years & $3.0[1.0,5.0]$ & $5.0[3.0,10.0]$ & 0.007 \\
\hline Diabetes treatment, n (\%) & & & 0.21 \\
\hline None & $13(14.1)$ & $7(6.5)$ & \\
\hline Diet & $5(5.4)$ & $2(1.9)$ & \\
\hline Oral agent & $65(70.7)$ & $79(73.1)$ & \\
\hline Insulin & $9(9.8)$ & $13(12.0)$ & \\
\hline Combination therapy & $0(0)$ & $7(6.5)$ & \\
\hline
\end{tabular}




\begin{tabular}{|c|c|c|c|}
\hline Arrhythmia, n (\%) & $84(79.2)$ & $97(82.9)$ & 0.485 \\
\hline Atrial fibrillation, n (\%) & $41(38.7)$ & $33(28.0)$ & 0.089 \\
\hline Beta blocker, n (\%) & $32(30.2)$ & $33(28.0)$ & 0.714 \\
\hline Calcium channel blocker, n (\%) & $94(88.7)$ & $94(79.7)$ & 0.067 \\
\hline Nitrates, n (\%) & $87(82.1)$ & $91(77.1)$ & 0.359 \\
\hline Diuretics, n (\%) & $40(37.7)$ & $44(37.3)$ & 0.945 \\
\hline ACE inhibitor/ARB, n (\%) & $82(77.4)$ & $93(78.8)$ & 0.793 \\
\hline Aspirin, n (\%) & $61(57.5)$ & $68(57.6)$ & 0.990 \\
\hline Antiplatelet, n (\%) & $105(99.1)$ & $116(98.3)$ & 0.999 \\
\hline Anticoagulant, n (\%) & $46(43.4)$ & $43(36.4)$ & 0.288 \\
\hline Inotropes, n (\%) & $105(99.1)$ & $116(98.3)$ & 0.999 \\
\hline Fasting blood sugar, mg/dl & $105.0[86.0,139.0]$ & $187.0[157.0,224]$ & $<0.001$ \\
\hline Blood urea nitrogen, mg/dl & $41.0[34.0,55.0]$ & $42.0[34.9,56.0]$ & 0.965 \\
\hline Creatinine, mg/dl & $0.90[0.74,1.10]$ & $0.82[0.71,1.10]$ & 0.432 \\
\hline Triglyceride, mg/dl & $109.0[82.0,157]$ & $146.0[108.0,188.0]$ & $<0.001$ \\
\hline Total cholesterol, mg/dl & $142.5[118.0,171.0]$ & $162.0[132.0,188.0]$ & 0.005 \\
\hline $\mathrm{LDL}, \mathrm{mg} / \mathrm{dl}$ & $83.0[67.0,113.0]$ & $103.5[74.0,122.0]$ & 0.1 \\
\hline $\mathrm{HDL}, \mathrm{mg} / \mathrm{dl}$ & $40 \pm 14.0$ & $37.5 \pm 9.6$ & 0.13 \\
\hline Hemoglobin, mg/dl & $12.8 \pm 1.6$ & $13.1 \pm 1.9$ & 0.134 \\
\hline $\mathrm{Na}, \mathrm{mg} / \mathrm{dl}$ & $142.7 \pm 3.7$ & $142.0 \pm 4.8$ & 0.582 \\
\hline $\mathrm{K}, \mathrm{mg} / \mathrm{dl}$ & $4.4 \pm 0.5$ & $4.4 \pm 0.5$ & 0.565 \\
\hline Ejection fraction, \% & $47.6 \pm 9.5$ & $48.4 \pm 9.2$ & 0.497 \\
\hline Hemoglobin A1c, mg/dl & $6.27 \pm 0.48$ & $8.86 \pm 1.39$ & $<0.001$ \\
\hline NYHA classification, n (\%) & & & 0.232 \\
\hline I & $14(14.3)$ & $14(14.3)$ & \\
\hline$\|$ & $48(49.0)$ & $56(57.1)$ & \\
\hline III & $28(28.6)$ & $26(26.5)$ & \\
\hline IV & $8(8.2)$ & $2(2.0)$ & \\
\hline Pump time, min & $90.0[70.0,130.5]$ & $93.0[67.0,120.0]$ & 0.584 \\
\hline Cross-clamp time, min & $58.0[42.0,82.0]$ & $56.0[43.5,74.5]$ & 0.961 \\
\hline Ventilation duration, hours & $11.2[8.5,15.0]$ & $12.0[8.5,15.5]$ & 0.636 \\
\hline ICU stay, hours & $51.7[25.0,116.5]$ & $47.7[25.0,96.0]$ & 0.735 \\
\hline
\end{tabular}

*P-value $<0.05$ was considered as statistically significant

+Variables with normal distribution are shown as mean \pm standard deviation, and distorted distributed variables are shown as median [interquartile range]

$A C E=$ angiotensin converting enzyme; $A R B=$ angiotensin-receptor blockers; $B M l=$ body mass index; $C A D=$ coronary artery disease; $\mathrm{COPD}=$ chronic obstructive pulmonary disease; $\mathrm{HDL}=$ high-density lipoproteins; ICU=intensive care unit; LDL=low-density lipoproteins; NYHA=New York Heart Association

showed no association between the level of HbA1c and major adverse cardiac events (including mortality) ${ }^{[12]}$. Additionally, although patients with $\mathrm{HbA1c}>6.5$ had more considerable glycemic variability in the mentioned study, this did not lead to a higher incidence of hyperglycemia or hypoglycemic episodes.
Wang et al. ${ }^{[13]}$ showed that $\mathrm{HbA} 1 \mathrm{c}$ is the only variable of diabetes that can independently predict long-term mortality following CABG. This supports the concept that rapid glucose adjustment right before the surgery is less beneficial than long-term glycemic control. Based on Halkos et al. ${ }^{[14]}$ study, $\mathrm{HbA} 1 \mathrm{c}>8.6 \%$ can involve 
Table 3. The unadjusted and adjusted regression model for the predictive effect of hemoglobin A1c on in-hospital mortality.

\begin{tabular}{l|c|c|c}
\multicolumn{1}{c|}{ Characteristic } & Odds ratio & 95\% confidence interval & $P$-value* \\
\hline Unadjusted & & & \\
\hline In-hospital mortality & 2.1 & $0.62-7.05$ & 0.227 \\
\hline Adjustedt & & & 0.38 - \\
\hline In-hospital mortality & 2.07 & & 0.91 \\
\hline
\end{tabular}

*P-value $<0.05$ was considered as statistically significant

†Adjusted for age, diabetes duration, low-density lipoprotein, and triglyceride level

a four-times risk of perioperative mortality in CABG patients. Another study has shown that not only can the elevated $\mathrm{HbA} 1 \mathrm{c}$ predict poorer outcomes following cardiac surgery, but also it is more observed in patients in low socioeconomic patterns ${ }^{[15]}$. Hudson et al. ${ }^{[16]}$ showed in their study on non-diabetic patients who underwent elective cardiac surgery that elevated $\mathrm{HbA} 1 \mathrm{c}$ is directly associated with higher short-term mortality. Some other similar studies also suggested the association between elevated $\mathrm{HbA1c}$ and mortality following cardiac surgery ${ }^{[17-19]}$.

It should be noted that most of the studies on the association of glycemic control with the outcomes of cardiac surgery have been performed on candidates for CABG, and this limits our ability to compare our findings with previously published data. As coronary artery disease is caused by atherosclerosis, a direct result of diabetes, most of these studies showed an independent association between elevated $\mathrm{HbA1c}$ and a higher rate of mortality and adverse outcomes. As atherosclerosis is not a common etiology for the valvular disease ${ }^{[20]}$, this can rationalize the findings of our study.

\section{Study Limitations}

The retrospective nature of our study limited our ability to find out more data on the in-hospital events and post-discharge survival of the patients. On the other hand, our center is a tertiary heart center, and it is probable that most referred patients were in a worse condition than the general population. Moreover, we did not have the data on the diabetes treatment and duration of diabetes in our study population to see whether the type of treatment and duration of the disease were related to in-hospital outcome and mortality. Finally, we only studied the in-hospital mortality of the patients, and it is presumed that by having longer follow-up results, we could find different results.

\section{CONCLUSION}

Overall, this study showed no association between preoperative $\mathrm{HbA} 1 \mathrm{c}$ levels and in-hospital mortality in candidates for valvular heart surgery. Future studies with a larger sample size should study the effect of HbA1c and glycemic control on the long-term survival of candidates for valvular heart surgery.
Financial support: Tehran Heart Center, internal fund, Tehran University of Medical Sciences, Tehran, Iran.

\section{No conflict of interest.}

\section{Authors' roles \& responsibilities}

MS

Substantial contributions to the conception or design of the work; or the acquisition, analysis, or interpretation of data for the work; drafting the work or revising it critically for important intellectual content; final approval of the version to be published

RJ Substantial contributions to the conception or design of the work; or the acquisition, analysis, or interpretation of data for the work; drafting the work or revising it critically for important intellectual content; final approval of the version to be published

MB Substantial contributions to the conception or design of the work; or the acquisition, analysis, or interpretation of data for the work; drafting the work or revising it critically for important intellectual content; final approval of the version to be published

SZ Substantial contributions to the conception or design of the work; or the acquisition, analysis, or interpretation of data for the work; drafting the work or revising it critically for important intellectual content; final approval of the version to be published

AR Substantial contributions to the conception or design of the work; or the acquisition, analysis, or interpretation of data for the work; drafting the work or revising it critically for important intellectual content; final approval of the version to be published

LP Substantial contributions to the conception or design of the work; or the acquisition, analysis, or interpretation of data for the work; drafting the work or revising it critically for important intellectual content; final approval of the version to be published

AS Substantial contributions to the conception or design of the work; or the acquisition, analysis, or interpretation of data for the work; drafting the work or revising it critically for important intellectual content; final approval of the version to be published 
AJ Substantial contributions to the conception or design of the work; or the acquisition, analysis, or interpretation of data for the work; drafting the work or revising it critically for important intellectual content; final approval of the version to be published

SHM Substantial contributions to the conception or design of the work; or the acquisition, analysis, or interpretation of data for the work; drafting the work or revising it critically for important intellectual content; final approval of the version to be published

SHAT Substantial contributions to the conception or design of the work; or the acquisition, analysis, or interpretation of data for the work; drafting the work or revising it critically for important intellectual content; final approval of the version to be published

\section{REFERENCES}

1. CDC: Centers for Disease Control and Prevention. Diabetes Quick Facts [Internet]. [place unknown]: CDC, aug 06, 2019 [cited 2020 Mar 01]. Available from: https://www.cdc.gov/diabetes/basics/quick-facts.html

2. Esteghamati A, Etemad K, Koohpayehzadeh J, Abbasi M, Meysamie A, Noshad S, et al. Trends in the prevalence of diabetes and impaired fasting glucose in association with obesity in Iran: 2005-2011. Diabetes Res Clin Pract. 2014;103(2):319-27. doi:10.1016/j.diabres.2013.12.034.

3. Estrada CA, Young JA, Nifong LW, Chitwood WR Jr. Outcomes and perioperative hyperglycemia in patients with or without diabetes mellitus undergoing coronary artery bypass grafting. Ann Thorac Surg. 2003;75(5):1392-9. doi:10.1016/s0003-4975(02)04997-4.

4. Nichols GA, Reinier K, Chugh SS. Independent contribution of diabetes to increased prevalence and incidence of atrial fibrillation. Diabetes Care. 2009;32(10):1851-6. doi:10.2337/dc09-0939.

5. Karamnov S, Brovman EY, Greco KJ, Urman RD. Risk factors and outcomes associated with sepsis after coronary artery bypass and open heart valve surgeries. Semin Cardiothorac Vasc Anesth. 2018;22(4):359-68. doi:10.1177/1089253218785362.

6. Abbaszadeh S, Shafiee A, Bina P, Jalali A, Sadeghian S, Karimi A. Preoperative hemoglobin A1c and the occurrence of atrial fibrillation following on-pump coronary artery bypass surgery in type-2 diabetic patients. Crit Pathw Cardiol. 2017;16(1):37-41. doi:10.1097/HPC.0000000000000103.

7. American Diabetes Association. Standards of medical care in diabetes--2014. Diabetes Care. 2014;37 Suppl 1:S14-80. doi:10.2337/dc14-S014.

8. Subramaniam B, Lerner A, Novack V, Khabbaz K, Paryente-Wiesmann
M, Hess $P$, et al. Increased glycemic variability in patients with elevated preoperative $\mathrm{HbA} 1 \mathrm{C}$ predicts adverse outcomes following coronary artery bypass grafting surgery. Anesth Analg. 2014;118(2):277-87. doi:10.1213/ ANE.0000000000000100.

9. Abbasi K, Karimi A, Abbasi SH, Ahmadi SH, Davoodi S, Babamahmoodi A, et al. Knowledge management in cardiac surgery: the second tehran heart center adult cardiac surgery database report. J Tehran Heart Cent. 2012;7(3):111-6.

10. Gandhi GY, Nuttall GA, Abel MD, Mullany CJ, Schaff HV, Williams BA, et al. Intraoperative hyperglycemia and perioperative outcomes in cardiac surgery patients. Mayo Clin Proc. 2005;80(7):862-6. doi:10.4065/80.7.862.

11. Lazar HL, Chipkin SR, Fitzgerald CA, Bao Y, Cabral H, Apstein CS. Tight glycemic control in diabetic coronary artery bypass graft patients improves perioperative outcomes and decreases recurrent ischemic events. Circulation. 2004;109(12):1497-502. doi:10.1161/01.CIR.0000121747.71054.79.

12. Bardia A, Khabbaz K, Mueller A, Mathur P, Novack V, Talmor D, et al. The association between preoperative hemoglobin $\mathrm{A} 1 \mathrm{C}$ and postoperative glycemic variability on 30-day major adverse outcomes following isolated cardiac valvular surgery. Anesth Analg. 2017;124(1):16-22. doi: 10.1213/ ANE. 0000000000001715 .

13. Wang TK, Woodhead A, Ramanathan T, Pemberton J. Relationship between diabetic variables and outcomes after coronary artery bypass grafting in diabetic patients. Heart Lung Circ. 2017;26(4):371-5.

14. Halkos ME, Lattouf OM, Puskas JD, Kilgo P, Cooper WA, Morris CD, et al. Elevated preoperative hemoglobin Alc level is associated with reduced long-term survival after coronary artery bypass surgery. Ann Thorac Surg. 2008:86(5):1431-7. doi:10.1016/j.athoracsur.2008.06.078.

15. Finger B, Brase J, He J, Gibson WJ, Wirtz K, Flynn BC. Elevated hemoglobin A1C is associated with lower socioeconomic position and increased postoperative infections and longer hospital stay after cardiac surgical procedures. Ann Thorac Surg. 2017;103(1):145-51. doi:10.1016/j.athoracsur.2016.05.092.

16. Hudson CC, Welsby IJ, Phillips-Bute B, Mathew JP, Lutz A, Chad Hughes $\mathrm{G}$, et al. Glycosylated hemoglobin levels and outcome in non-diabetic cardiac surgery patients. Can J Anaesth. 2010;57(6):565-72. doi:10.1007/ s12630-010-9294-4.

17. Faritous Z, Ardeshiri M, Yazdanian F, Jalali A, Totonchi Z, Azarfarin R. Hyperglycemia or high hemoglobin A1C: which one is more associated with morbidity and mortality after coronary artery bypass graft surgery? Ann Thorac Cardiovasc Surg. 2014;20(3):223-8. doi:10.5761/atcs.oa.13.02282.

18. Knapik P, Cieśla D, Filipiak K, Knapik M, Zembala M. Prevalence and clinical significance of elevated preoperative glycosylated hemoglobin in diabetic patients scheduled for coronary artery surgery. Eur J Cardiothorac Surg. 2011;39(4):484-9. doi:10.1016/j.ejcts.2010.07.037.

19. Tennyson C, Lee R, Attia R. Is there a role for $\mathrm{HbA1c}$ in predicting mortality and morbidity outcomes after coronary artery bypass graft surgery? Interact Cardiovasc Thorac Surg. 2013;17(6):1000-8. doi:10.1093/icvts/ivt351.

20. Boudoulas KD, Borer JS, Boudoulas H. Etiology of valvular heart disease in the 21st century. Cardiology. 2013;126(3):139-52. doi:10.1159/000354221. 